\title{
Reply to comment by Morteza Mehdizadeh on the publication "The effect of acute hyperglycemia on retinal thickness and ocular refraction in healthy subjects" by Nanouk G.M. Wiemer et al.
}

\author{
Nanouk G. M. Wiemer • Michiel Dubbelman
}

Received: 28 February 2008 / Accepted: 3 March 2008/ Published online: 20 May 2008

(C) The Author(s) 2008

\section{Dear Editor,}

In our study, we measured the retinal thickness and ocular refractive error in healthy subjects during acute induced hyperglycemia. In one subject, we found a hyperopic shift of $0.4 \mathrm{D}$, which could not be explained by a change in retinal thickness. Therefore, we proposed that other refractive components, such as the lens, are involved in causing blurred vision and refractive alterations during hyperglycemia. In a comment on our article, Dr. Mehdizadeh draws attention to the fact that the hyperopic shift in refraction could also be explained by a change in the refractive index of the aqueous humor and the vitreous. Subsequently, Dr. Mehdizadeh shows by calculation that a change in the refractive index of the aqueous and vitreous of $1 / 1000$ would induce a change in the summation of the refractive power of the posterior corneal surface, and the anterior and posterior lens surface of $0.12 \mathrm{D}$.

We agree with Dr. Mehdizadeh that the possible role of a change in the refractive index of the aqueous and vitreous should be considered before it can be concluded that a change in refractive error is caused by changes in the lens.

\footnotetext{
N. G. M. Wiemer $(\bowtie)$ P.O. Box 7057, 1007 MB Amsterdam, The Netherlands

e-mail: ngm.wiemer@vumc.nl

N. G. M. Wiemer • M. Dubbelman

Institute for Research in Extramural Medicine,

VU University Medical Center,

Amsterdam, The Netherlands

M. Dubbelman

Department of Physics and Medical Technology,

VU University Medical Center,

Amsterdam, The Netherlands
}

Department of Ophthalmology, VU University Medical Center,
However, we think that the latter is the case. Firstly, it is probable that the value of the change in the refractive index of the aqueous and vitreous of $1 / 1000$, which was used in the comment, is rather large. This value was based on the study of Liu et al. [6], in which it was found that a change in glucose concentration of $0.1 \%(0.1 \mathrm{mg} / \mathrm{dl}$ or $1.0 \mathrm{mmol} / \mathrm{l})$ is equal to a change in the refractive index of the aqueous humor of $1.4 \times 10^{-4}(1 / 10000)$. Nevertheless, in more recent studies of Kohl et al. [5] and Esenaliev et al. [2], a change in the refractive index of the aqueous was found that was six times smaller (approximately $2.5 \times 10^{-5}$ per increase in glucose levels of $1.0 \mathrm{mmol} / \mathrm{l})$. However, if the large value of $1 / 1000$ is used to calculate the change in refractive error, our calculations show a smaller change in refraction than the change in refractive error that was obtained in the comment. Our results differ, because the calculations in the comment were performed with a value of the refractive index of the lens (1.387), which is based on the refractive index of the cortex of the lens [1]. Instead, the equivalent refractive index of the lens as a whole, which is 1.427 [3, 4], should be included in the calculations. Another reason why our calculations are different is that in the comment the sum of the change in the refractive power of the posterior corneal surface and of the anterior and posterior lens surfaces is used to draw conclusions about a change in the refractive error of the whole eye. However, the change in refractive power in the eye (e.g., in the lens) is not equal to the change in refractive error. For example, a change in intraocular lens power of $0.5 \mathrm{D}$ only gives a change in the refractive error of the eye of $0.34 \mathrm{D}$ [7]. Thus, in order to calculate the effect of a change in the refractive index of the aqueous and vitreous on ocular refraction, all geometric eye parameters (i.e., the thickness of the cornea and the lens, the radius of curvature of the anterior 
and posterior surfaces of the cornea and the lens, the refractive indices of the cornea, aqueous, lens and vitreous, and the axial eye length) should be taken into account.

In that case, calculation makes it clear that an increase in the refractive index of the aqueous and vitreous of $1 / 1000$ would induce a change in ocular refraction of $0.08 \mathrm{D}$ in subject 01 of our study, assuming that the other geometric ocular parameters were unaltered. This is too small to explain the hyperopic shift of $0.4 \mathrm{D}$ found in our article. Finally, an important reason why we stated in our study that the change in refraction was caused by the lens is that we actually measured a change in the shape and the equivalent refractive index of the lens during hyperglycemia. This finding will be published in another article [8], and as a result we concluded that it is most likely that the observed hyperopic shift is caused by changes in the lens.

Open Access This article is distributed under the terms of the Creative Commons Attribution Noncommercial License which permits any noncommercial use, distribution, and reproduction in any medium, provided the original author(s) and source are credited.

\section{References}

1. Atchison DA, Smith G (2000) Optics of the Human Eye. Appendix 3: Schematic eyes. Butterworth Heinemann, Oxford

2. Esenaliev RO, Larin KV, Larina IV (2001) Noninvasive monitoring of glucose concentration with optical coherence tomography. Optics Letters 26:992-994

3. Garner LF, Smith G (1997) Changes in equivalent and gradient refractive index of the crystalline lens with accommodation. Optom Vis Sci 74:114-119

4. Garner LF, Yap MK (1997) Changes in ocular dimensions and refraction with accommodation. Ophthalmic Phys Opt 17:12-17

5. Kohl M, Cope M (1994) Influence of glucose concentration on light scattering in tissue-simulating phantoms. Optics Letters 19: 2170-2172

6. Liu Y, Hering P, Scully MO (1992) An integrated optical sensor for measuring glucose concentration. Applied Physics B: Lasers and Optics 54:18-23

7. Shammas HJ (2003) Intraocular Lens Power Calculations, Slack Inc., Thorofare NJ

8. Wiemer NG, Eekhoff EM, Simsek S, Heine RJ, Ringens PJ, Polak BC, Dubbelman M (2008) The effect of acute hyperglycemia on retinal thickness and ocular refraction in healthy subjects. Graefe's Clin Exp Ophthalmol [Epub ahead of print] 